\title{
Nutritional, phytochemical and commercial quality of Noni fruit: a multi-beneficial gift from nature
}

\begin{abstract}
Morinda citrifolia L., ñNoniò, has been used as a food and traditional medicine in Polynesian culture. Noni is now widely available in the global market, mainly as juices and dietary supplements. Here, we review recent research on Noni and its products. We summarize research on the beneficial therapeutic and nutritional properties of Noni, as well as that on the effects of post-harvest storage and processing methods on the properties of Noni products. The aim of this review is to provide a comprehensive data on the technical and nutritional advances related to Noni fruit, including those described in recent patents.
\end{abstract}

Keyword: Noni fruit; Beneficial therapeutic; Nutritional properties 